\title{
Towards an integrated approach to cohesion and coherence in interlingual subtitling
}

\author{
Kajingulu Somwe Mubenga \\ Department of Afrikaans and Dutch, Stellenbosch University, 7600 Stellenbosch, South Africa \\ Email: ksmubenga@sun.ac.za
}

\begin{abstract}
This paper is written from the perspective of systemic functional linguistics (Halliday 1978). In this perspective, a text is a semantic unit that has a particular function and is related to its social system via its context of situation and of culture (Eggins 1994; Halliday and Hasan 1985). These inherent properties of a text hold true for a translated text as well. Since translation is an act of communication, priority is given to functional equivalence (Waard and Nida 1986) and norms (Toury 1995). The aim of this paper is to propose an integrated approach - an approach that combines linguistic and nonlinguistic resources - to cohesion and coherence in interlingual subtitling since this has not yet been done in translation studies. Thus, the paper is purely theoretical in nature. It is divided into four sections. The first section is an introduction to the notions of cohesion and coherence. The second section discusses current theories of cohesion and coherence. The third section reviews various approaches to these notions. In the final section, an integrated approach is proposed as a viable approach to cohesion and coherence in interlingual subtitling. Advantages and implications of this integrated approach are highlighted for further research.
\end{abstract}

Keywords: integrated approach, cohesion, coherence, interlingual subtitling, metafunctional semiotic theory

\section{Introduction}

The notions of cohesion and coherence have a long tradition in the linguistic literature. They date back to ancient rhetoric where they were used by Greek and Roman philosophers and orators such as Aristotle, Plato, Catiline and Cicero whose speeches and writings have served as models of cohesive and coherent language. In modern linguistics, these notions are considered as two facets of the same coin. They are related to syntagmatic and paradigmatic relations developed by the late Swiss linguist Ferdinand de Saussure in his course in general linguistics (see De Saussure 1959, 1972 [1916]).

Syntagmatic relations are those relations that are equated with the linear structure of language whereby the value of an individual term is determined by its relationship with the terms that precede and follow it. For example, in the sentence the cat is on the mat, the elements the, cat, $i s$, on, the, and mat are in a syntagmatic relationship. 
Paradigmatic relations are those in which words are associated with other similar words through being contrasted or substitutable in a given context. For instance, in the sentences the cat is on the mat and the dog is on the table, the word cat is in a paradigmatic relationship with the word $d o g$. In the same way, the word mat is in a paradigmatic relationship with the word table.

These relations of co-occurrence and substitution or comparability have led to the notions of cohesion and coherence developed in mainstream linguistics and translation studies (TS). These notions are the object of the present paper. My interest in cohesion and coherence is that they are potential areas of research in audiovisual translation (AVT) in general and in interlingual subtitling in particular (cf., for example, Díaz Cintas 2004:63). It is my contention that research on cohesion and coherence in interlingual subtitling will reveal the shifts that occur in the translation of cohesive markers from the source text (ST) into the target text (TT) because of the constraints of time and space, as well as the principle of relevance imposed on the subtitles.

\section{Major theories of cohesion and coherence}

Cohesion and coherence are mainly regarded as the links that hold between clauses or sentences in a text and give both grammatical and semantic meaning to that text. These links are needed to establish the grammatical and lexical relationships between the elements that occur in adjacent clauses or sentences. While cohesion refers to surface structure relationships, coherence is often related to deep structure relationships. There are three major theories of cohesion and coherence that have been influential. These theories are well articulated by Halliday and Hasan (1976), De Beaugrande and Dressler (1981), and Brown and Yule (1983) and constitute the theoretical base of the present paper.

\subsection{Halliday and Hasan's theory}

Working in the framework of systemic functional linguistics, Halliday and Hasan (1976) focused on linguistic or textual cohesion to develop their theory. In discussing textual cohesion, they presented the basic tools that determine whether or not sets of sentences constitute a text. These tools are linguistic features which can be identified in a text. The features contribute to the text's unity and create its texture or its status of being a text. On this point, Halliday and Hasan (1976:2) make the following statement: "A text has texture and this is what distinguishes it from something that is not a text.... The texture is provided by the cohesive RELATION that exists between [items of information]."

In this respect, Halliday and Hasan consider cohesion a semantic concept which refers to relations of meaning that exist within a text and define it as a text. The latter is, according to these authors, considered as any spoken or written passage, of whatever length, that forms a unified whole. In this case, the text is thus a semantic unit. It is related to a clause or sentence not by size but by realisation. This means that a text does not consist of sentences but it is realised by, or encoded in, sentences that hang together through cohesive relationships.

In their treatment of cohesion, Halliday and Hasan provided a taxonomy of cohesive devices and, for the first time, made a distinction between grammatical and lexical cohesion. Grammatical cohesion is based on reference, substitution and ellipsis. Lexical cohesion is realised by the selection of vocabulary items. The cohesive device of conjunction is on the borderline between grammatical and lexical cohesion. This also suggests that the two types of 
cohesion are inextricably intertwined. However, following Lehmann (1985:107), it may be argued that it is lexical cohesion that greatly contributes to the empirical knowledge of textuality.

In addition to cohesion as conceived of by Halliday and Hasan (1976), it is important to take into account both textual structure and macrostructure. The latter defines the genre or texttype such as a conversation, a novel, a letter or a medical report. The former occurs within a clause and is described in terms of the Functional Sentence Perspective (FSP) discussed earlier by, for example, Daneš (1974). Halliday and Hasan (1976:13) implicitly recognised these additional cohesive relations as is evident in the following:

There are, of course, other types of semantic relation associated with a text which are not embodied in this concept [of cohesion]; but the one that it does embody is in some ways the most important, since it is common to text of every kind and is, in fact, what makes a text a text.

Finally, although Halliday and Hasan (1976:229) recognise that there is a distinction between cohesion and coherence, they continue focusing on the presence of cohesive markers as the only factor that matters in the construction of a text. This is one of the limitations of Halliday and Hasan's (1976) theory of cohesion that is rather more descriptive and less formalised. However, the value of their theory lies in having elaborated the taxonomy of cohesive markers and semantic relationships that contribute to texture and, in doing so, having paved the way for De Beaugrande and Dressler (1981) and Brown and Yule (1983) to develop their theories of cohesion and coherence.

\subsection{De Beaugrande and Dressler's theory}

Working in the area of text linguistics, De Beaugrande and Dressler (1981) made a clear and neat distinction between cohesion and coherence. For them, the two concepts contribute to the stability of the text as system. Cohesion is related to the continuity of occurrences realised by syntax, and operates in short-term or working memory. Coherence is related to the continuity of senses encoded in a configuration of concepts and relations, and operates in long-term or semantic memory.

Like Halliday and Hasan (1976), De Beaugrande and Dressler (1981) outlined their taxonomy of cohesive devices. This taxonomy consists mainly of recurrence, partial recurrence, parallelism, paraphrase, pro-forms, ellipsis, tense, aspect, junction, and FSP (to which should be added intonation in the case of spoken texts). Adopting the grammar of Augmented Transition Networks (ATNs) first developed in Artificial Intelligence by, for instance, Woods (1970), De Beaugrande and Dressler (1981:50-53) have successfully shown how and in what order cohesive links are created within the major units of syntax, viz., the phrase, the clause and the sentence, and among two or more of these same units. They thus conclude their application of ATNs to text analysis in the following terms: 
In closely-knit units such as phrases, clauses, and sentences, cohesion is upheld by fitting elements into short-range grammatical dependencies. In long-range stretches of text, the major operation is discovering how already used elements and patterns can be re-used, modified, or compacted. [This function is fulfilled by such cohesive devices as recurrence, paraphrase, pro-forms, ellipsis and junction] via repetition, substitution, omission, and signalling relationships (emphasis in the original).

(De Beaugrande and Dressler 1981: 54)

De Beaugrande and Dressler (1981) have explained at great length and through their procedural approach how the different cohesive devices contribute to textuality which rests on the principle of continuity. This continuity operates not only among the surface structures of phrases, clauses and sentences but also between concepts and relations, as well as text-world events and situations. The latter are signalled by the device of junction or the "use of junctive expressions" (De Beaugrande and Dressler 1981:71). Among these expressions, it is the large category of subordinating junctives such as because, since, when and while that makes the common types of coherence relations explicit. When these devices are missing in text, noticeable gaps are generally filled by "updating" (De Beaugrande and Dressler 1981:70) or making inferences about how the text-world is evolving. Other devices which overtly signal relations within or among text-world events and relations are tense, aspect, FSP and intonation. These devices operate on the borderline between cohesion and coherence.

As far as coherence is concerned, De Beaugrande and Dressler have again used ATNs to demonstrate and explain how language users process and understand a text. Coherence is viewed as making sense of the text. As De Beaugrande and Dressler (1981:109) rightly point out, coherence is "the outcome of actualizing meanings in order to make 'sense' [of a text]." The use of ATNs or syntactic parsers is advantageous in that it shows us how language users create expectations and develop strategies for processing, making sense of, and understanding a text. The reader is referred to De Beaugrande and Dressler (1981:109) for an outline of these strategies.

For this researcher, De Beaugrande and Dressler depart from Halliday and Hasan's theory in that they are much more interested in developing cognitive strategies for processing, making sense of, and understanding texts. For them, a text is coherent only when language users can make sense of it and understand it. Thus, the merit of their theory of cohesion and coherence lies in (i) the use of ATNs to parse the phrases, clauses and sentences and show the cohesive links in text analysis, (ii) the development of cognitive strategies for text comprehension, and

(iii) the introduction of a procedural approach to both text cohesion with a focus on microstructures and text-world coherence with an emphasis on macrostructures.

\subsection{Brown and Yule's theory}

Working in the area of discourse analysis, Brown and Yule (1983) developed a theory of cohesion and coherence that is partly based on that of Halliday and Hasan (1976) in the case of cohesion and partly related to that of De Beaugrande and Dressler (1981) in the case of coherence. As far as cohesion is concerned, Brown and Yule (1983:190) have this to say:

In this section we shall give a brief outline of the account provided by Halliday and Hasan (1976) since this is by far the most comprehensive treatment of the subject and has become the standard text in this area. 
However, it is important to notice that besides this brief outline Brown and Yule (1983:199204) focused their discussion on such cohesive markers as endophora and substitution. As for the distinction between endophora and exophora, Brown and Yule (1983: 201) adopt a different view from that of Halliday and Hasan (1976) and thus suggest that, in both cases, text receivers have to look into their mental representation to determine reference. In the case of endophora, for example, they have a mental representation of what is in the text, i.e., a world created by the discourse. In the case of exophora, they have a mental representation of what is outside the text, i.e., what is in the world beyond the text. As regards substitution, Brown and Yule (1983:204) point out that Halliday and Hasan's model of cohesion does not "accommodate the various connections which do exist in texts" since they are mainly concerned with providing the linguistic resources that mark cohesive relationships rather than with how language users understand texts. Brown and Yule's view is also adopted here.

Interestingly, Brown and Yule (1983:204-222) have gone one step further by adopting what seems to be a pragmatic approach to the discussion of discourse reference and pronouns in discourse. Concerning discourse reference, it may be argued in line with Brown and Yule (1983:205) that "[s]uccessful reference depends on the hearer's identifying for the purposes of understanding the current linguistic message, the speaker's intended referent, on the basis of the referring expression used." This speaker-hearer perspective in the identification of discourse reference is an introduction to pragmatics and psychology of comprehension which are not used in Halliday and Hasan's theory of cohesion.

Regarding pronouns in discourse, Brown and Yule (1983:222) have discussed several examples and come to the conclusion that the interpretation of pronominal reference in decontextualised sentence pairs is sometimes misleading and, therefore, suggest that this interpretation "should be based on more naturally occurring discourse of different types." This point might well stimulate further research on the function of pronouns in multimodal discourse such as film and advertising. For example, the translation of the personal pronoun you into vous or $t u$ in French will depend on the interpersonal or role relationships of characters in the film.

As far as coherence is concerned, Brown and Yule (1983:224-225) adopt Gricean pragmatics and suggest that the most important thing about using the assumption of coherence "is the reader's (or hearer's) effort to arrive at the writer's (or speaker's) intended meaning in producing a linguistic message." This assumption of coherence will discourage the text receivers to interpret any message literally. In this respect, Brown and Yule (1983:225) propose three basic strategies for interpreting the intended meaning of any spoken or written discourse. These strategies are (i) computing the communicative function, (ii) using general sociocultural knowledge, and (iii) determining the inferences to be made.

In order to explain how the above-mentioned strategies work to achieve coherence in discourse, Brown and Yule (1983) have relied on the techniques used in conversation analysis with the management of turn-taking and adjacency pairs, the notion of speech acts adopted from Austin's $(1962)$ and Searle's $(1969,1975)$ speech act theory, and the notion of top-down and bottom-up processing derived from Artificial Intelligence. In addition to this, Brown and Yule (1983:236-255) discussed in some detail a wide range of knowledge structures or "global patterns" (De Beaugrande and Dressler 1981:90) such as schemas, frames and scripts used in the interpretation and comprehension of discourse. Finally, Brown and Yule (1983:256-270) described a set of inferences that people make to understand discourse in 
terms of missing links, non-automatic connections and gap filling processes. Because of a large number of inferences in language, including bridging, elaborative, evaluative and reductive inferences (for further details, see Brown and Yule 1983:268-269), it is suggested here that people make reasonable inferences in arriving at an interpretation and comprehension of discourse.

From what is said above, it appears that Brown and Yule's (1983) theory of cohesion and coherence has advanced quite far but is still descriptive. The merit of their theory lies in their elaboration on discourse and pronominal reference in the treatment of cohesion, the introduction of the notions of speech acts, adjacency pairs, turn-taking and both top-down and bottom-up processing in the treatment of coherence, and their more detailed discussion of inferences that are made to understand a piece of coherent discourse. This brief survey of the major theories of cohesion and coherence opens the door to a variety of approaches that have influenced research on cohesion and coherence in TS and to which we turn in the following section.

\section{Approaches to cohesion and coherence in translation studies}

Cohesion and coherence are issues that have always played a key role in translation theory and practice. This has led translation scholars to develop different approaches to cohesion and coherence following the three major theories surveyed earlier. Unfortunately, no review of these approaches has ever been done in TS to the best of my knowledge and this section undertakes to do so. This paper focuses on Baker (1992), Bell (1991), Blum-Kulka (1986), Folkart (1988), Hatim and Mason (1990, 1997), Kostopoulou (2007), and Newmark (1987, $1988,1991)$. The main reason for this focus is that these scholars represent different approaches which are in current practice in TS and are of interest to researchers working in interlingual subtitling. Their writings may serve as guidelines and thus not only suggest the directionality of research on cohesion and coherence in film translation but also pave the way for a new approach to be proposed in section 4.

\subsection{Baker's approach}

As far as cohesion is concerned, Baker (1992: chapter 6) adopted Halliday and Hasan's (1976) theory. She defines cohesion in the following terms:

Cohesion is the network of lexical, grammatical, and other relations which provide links between various parts of a text. These relations or ties organize and, to some extent create a text, for instance by requiring the reader to interpret words and expressions by reference to other words and expressions in the surrounding sentences and paragraphs. Cohesion is a surface relation; it connects together the actual words and expressions that we can see or hear (...).

(Baker 1992:180)

In this respect, Baker focuses on the grammatical cohesive devices of reference, substitution, ellipsis, conjunction and on lexical cohesion. She explores the relevance of these cohesive devices to translation and takes a speaker/writer - hearer/reader perspective to explain how they are used in English and other languages including Hebrew, Brazilian Portuguese, Japanese, German and Arabic. The merit of Baker's (1992:211) approach lies in having shown through concrete examples that there are differences between languages in the use of cohesive devices. These differences should be taken into account to establish equivalence at the textual 
level. A valuable application of this linguistic cohesion to translation is provided by Kachroo (1984) and the reader is referred to the latter for further details.

As for coherence, Baker (1992:217-218) adopted Brown and Yule's (1983) theory. In this regard, coherence is viewed as one of the central notions that directly relate to pragmatics and help hearers/readers to make sense of what they hear or read. It is also a problematic area in cross-cultural communication and therefore should be given due attention in translation. While cohesion deals with the surface relations within a text and relates to grammatical dependencies in the creation of text, coherence is concerned with the conceptual or semantic relations underlying the surface text and thus relates to meaning dependencies as they are perceived by the text receiver.

Furthermore, Baker (1992:222-228) considers coherence to be relevant to the interpretation of spoken and written discourse. Very often, when cohesive devices are not explicitly signalled in a text, people "provide the necessary links to render the discourse coherent" (Baker 1992:223). They do so through supplemental and explanatory coherence (cf., for example, Charolles 1983:93; Baker 1992:223) and through making pragmatic inferences. This making of pragmatic inferences contributes to maintaining the coherence of spoken and written discourse.

In the context of translation, maintaining coherence in the TT is an important strategy for avoiding problems of mistranslation and misinterpretation. This maintenance can be achieved by, for instance, identifying references to participants and entities in both the ST and the TT. It can also be achieved by interpreting the significance of a given reference and the way it links to other features of the context and co-text. In other cases, as Baker (1992:238) suggests, the translator will have to decide what to omit or to replace in the TT so as not to violate one or more of the maxims of the Co-operative Principle (Grice 1975) and the Principle of Politeness (Leech 1983), both of which are interpreted differently across cultures. In the end, Baker (1992:253) rightly observes that the translator will have to "minimise [serious] discrepancies between the model of the world presented in the source text and that with which the target reader is likely to be familiar." In other words, the translator has to work out implied meanings in translation so as to establish pragmatic equivalence and enable the target reader to understand the recreated message clearly.

\subsection{Bell's approach}

Bell (1991:164-165) developed his approach to cohesion and coherence using a mixture of terminology. He discusses cohesion and coherence in terms of standards of textuality and defines them along the same lines as De Beaugrande and Dressler (1981). Interestingly, he adds a new dimension to this definition by referring to aspects of systemic functional grammar as follows:

Cohesion is, then, concerned with the manipulation of selections from the options available in the MOOD system; Subject, Predicator, Complement, Adjunct, etc. (...). Coherence, in contrast, [deals with the manipulation of] the propositional structures (Actor, Process, Goal, Circumstances, etc.) which are the creation of the systems of TRANSITIVITY (...).

(Bell 1991:165)

However, Bell's (1991:165-167) discussion of cohesion and coherence is limited to some examples clearly distinguishing these two terms and also raising a number of questions for the 
translators. The latter have to appeal to their knowledge of the world and find ways of relating both the real world and the text world in order to make sense of the text they are processing.

\subsection{Blum-Kulka's approach}

Blum-Kulka (1986) adopted what she calls a communicative and discoursal approach to address the issue of shifts of cohesion and coherence in the translation of written texts. Like other translation scholars, she makes a clear-cut distinction between cohesion and coherence and defines them by referring to the latter as a covert relationship and the former as an overt relationship in the following terms:

Coherence can be viewed as a covert potential meaning relationship among parts of a text, made overt by the reader or listener through processes of interpretation. For this process to be realized, the reader or listener must be able to relate the text to relevant and familiar worlds, either real or fictional. Cohesion, on the other hand, will be considered as an overt relationship holding between parts of the text, expressed by language specific markers (emphasis in the original). $\quad$ (Blum-Kulka 1986:17)

As for the shifts in cohesion, Blum-Kulka (1986:18-23) discusses two major types: (i) shifts in levels of explicitness, and (ii) shifts in text meaning. The first type refers to the grammatical differences between languages resulting from changes in the types of ties which are used to mark cohesion in the ST and the TT. Such shifts are often linked to differences in stylistic preferences for the types of cohesive markers in the two or more languages which are involved in translation. In general, the level of textual explicitness in the TT may be higher or lower than that in the ST. The second type of shift relates to the changes that occur in the explicit and implicit meaning potential of the ST through translations. Such functional shifts have far-reaching consequences for the interpretation of meanings in the TT. They can be explained in terms of what Blum-Kulka (1986:19) refers to as the "explicitation hypothesis."

As regards the shifts in coherence, Blum-Kulka (1986:23-32) again distinguishes between two basic types: (i) reader-focused shifts, and (ii) text-focused shifts. The latter are linked to the process of translation per se, and the former to a change in reader audiences through translation. Blum-Kulka uses the cohesive tie of reference to illustrate the reader-focused shifts of coherence in translation. As for the text-focused shifts of coherence, she argues that they often arise from the translator's failure to realise the functions that a particular linguistic system or form plays in conveying indirect meanings in a given text (Blum-Kulka 1986:30). Thus, she uses indirect speech acts to illustrate how text-focused shifts of coherence arise when these speech acts are translated literally.

Since this study into shifts of cohesion and coherence in translation is largely exploratory, Blum-Kulka (1986:32-34) suggests that empirical studies on a large-scale basis are needed to confirm or reject her findings. Contrastive stylistic study will be relevant and appropriate to investigate shifts of cohesion, and discourse-oriented psycholinguistic study to investigate shifts of coherence. It is interesting to note that in recent years such studies are beginning to burgeon in TS. A case in point is Gumul's (2008) study into the translation of conjunctive cohesive markers in simultaneous and consecutive interpreting. In this study, the overall results reveal that, owing to the interpreting constraints, there is a statistically significant difference between the two modes of interpreting in the rendition of conjunctive cohesive markers. The results indicate that there is retention of the same category of cohesive markers 
in simultaneous interpreting whereas categorical shifts and omissions are frequent in consecutive interpreting.

\subsection{Folkart's approach}

Working in the area of translation didactics or the teaching of translation, Folkart (1988) adopted a semiotically-driven approach to cohesion. She developed this approach by taking into account form rather than substance and by moving from morphemes to the entire text. Folkart (1988:148-154) limited herself to developing a wide range of exercises for training students in recognising form in the ST and reconstituting it in the TT. Recognition exercises have been designed at the infrasentential, sentential and suprasentential or textual ranks. Students are then given an opportunity to map them onto the discourse-level structures of the TT.

Although Folkart has focused on exercises of a linguistic type, the merit of her approach lies in her introduction of a semiotic dimension in TS, not as an alternative to the different approaches oriented towards linguistics but as a complement to them. For this researcher, a semiotic approach to cohesion and coherence is very promising especially in the context of AVT in general and in interlingual subtitling in particular. Since film is a semiotic construct, such an approach may help subtitlers to analyse aspects of acoustic and visual cohesion in the filmic text. This point is taken up further in section 4.

\subsection{Hatim and Mason's approach}

Hatim and Mason $(1990,1997)$ have developed their approach to cohesion and coherence along De Beaugrande and Dressler's (1981) lines. They have considered cohesion and coherence as two dimensions of the standards of textuality in their model of text analysis (Hatim and Mason 1990:195, 1997:21). Cohesion is the first standard and is defined in terms of sequential connectivity of surface elements. Coherence, in contrast, is the second standard and refers to conceptual connectivity that comprises (i) logical relations, (ii) organisation of events, objects and situations, and (iii) continuity of human experience. Both these standards contribute to the creation and development of textual communication.

In their treatment of cohesion and coherence, Hatim and Mason (1990) have not only raised a good number of translation issues but have also proposed remedies or suggestions for these same issues. Among the elements discussed in relation to cohesion and coherence are (i) recurrence and co-reference, (ii) partial reference, (iii) pro-forms and ellipsis, (iv) collocation, (v) junction and inter-propositional coherence, (vi) explicit and implicit relations, and (vii) FSP. These are almost the same elements as those discussed by Baker (1992), except for FSP. The latter is considered as one of the higher-order variables of texture which refers to the basic organisation of the clause in terms of Theme and Rheme and thus contributes to surface cohesion in discourse. Further details on this element and its variables can be found in Hatim and Mason (1990:212-220).

\subsection{Kostopoulou's approach}

In recent years, Kostopoulou (2007) has focused on what she calls a communicative text linguistic approach to coherence in translation didactics. This approach is based on De Beaugrande and Dressler's theory of cohesion and coherence. In this respect, Kostopoulou suggests that such basic concepts as knowledge, frames, scripts and memory are necessary for the description and examination of coherence in a text as well as for the comprehension and interpretation of a text. Thus, they should be taken into account when selecting "high- 
coherence" or "low-coherence" texts (McNamara 2001) for translation purposes, something that is relevant to subtitlers for the selection and translation of films as well.

\subsection{Newmark's approach}

Focusing on cohesion, Newmark (1987:294-295, 1991:65, 69) has advocated the use of systemic linguistics in translation. He considers cohesion as one of the four levels of translating and thus "the most useful constituent of discourse analysis or text linguistics applicable to translation." This cohesive level is well articulated in his approach to translating (Newmark 1988:23-24). It is mainly concerned with (i) the structure and (ii) the moods of the text. The structure refers to the connectives that link the sentences or items of information to each other within a text. It follows the train of thought. The mood is a dialectical factor that moves on a continuum between positive and negative or between emotive and neutral. It helps to trace the thread of a text through its value-laden and value-free expressions.

Finally, Newmark (1988:24) suggests that the cohesive level is "a regulator, it secures coherence, [and] it adjusts emphasis. ... This is where the findings of discourse analysis are pertinent." Translators have to look carefully at the connectives or those missing between sentences and decide how far they can intervene. This close examination of the connectives within a text is an important part of the revision in the translating process. Since connectives have different shades of meaning, finding the correct one(s) will be one of the translator's tasks to maintain equivalence between the ST and the TT (cf. Newmark 1987:295-296). This is a very good point that should be taken up in interlingual subtitling (see, for example, De Linde and Kay 1999:28-31 for further details on text cohesion in subtitling).

At this stage, it must be stated explicitly that the above review is not complete. Nor is it exhaustive. However, it shows the different points that are often discussed in TS in terms of cohesion and coherence and that may be integrated into one single approach. This is the focus of the following section.

\section{Proposals for an integrated approach to cohesion and coherence in interlingual subtitling}

Considering the different approaches reviewed above, we are in a position to say that they are complementary rather than alternatives to one another. They discuss the same things from different perspectives. This leads us to propose an approach that may contribute to the analysis of both cohesion and coherence in interlingual subtitling. Such an approach must take account of all the elements that occur in the film, namely, words, gestures, images, music and sound effects. In other words, it must take into account the acoustic, the verbal and the visual elements in the film. An approach that fulfils this condition is an integrated approach. The latter has some advantages over other approaches as well as some implications for further research on cohesion and coherence in interlingual subtitling as will become clear shortly.

\subsection{Advantages of an integrated approach to cohesion and coherence}

An integrated approach to cohesion and coherence is a flexible approach that combines the different elements or resources of both the linguistic and the non-linguistic dimensions. This integrated approach has a semiological focus already suggested by Folkart (1988) but extended here to include the non-linguistic resources so far neglected in the different approaches. For it to operate successfully in interlingual subtitling, it adopts Halliday's (1985, 2004) functional grammar for the analysis of grammatical elements, Kress and Van 
Leeuwen's $(1996,2006)$ grammar of visual design for the analysis of visual elements, and Van Leeuwen's (1999) theory of sound design for the analysis of acoustic elements. A common denominator to these three tools - that is, systemic functional grammar, the grammar of visual design and the grammar of sound design - is that they are semiotically-driven in that they all relate to the metafunctional semiotic theory developed by Halliday (1978).

In the AVT context, and more particularly in interlingual subtitling, this metafunctional semiotic theory has already been adopted by Mubenga (2008) (see also Mubenga 2009) to serve as the theoretical base of the Multimodal Pragmatic Analysis (henceforth MPA). The latter is a research methodology developed primarily to analyse film discourse in AVT but can also be applied to other types of multimodal discourse such as advertising messages or computer screen texts. It has three basic components and three levels of analysis that facilitate the analysis of all the linguistic and non-linguistic elements in the film.

As far as components are concerned, MPA consists of the functional, the semiotic and the cognitive components. The functional component is responsible for the grammatical or verbal elements. The semiotic component deals with the visual as well as the acoustic elements that occur in the film. The cognitive component is the central unit acting like the black box or the mind of the MPA. It is thus the place where the acoustic, the verbal and the visual information or elements integrate and interact with one another and with knowledge structures such as frames, scripts and schemas to make inferences.

As regards the levels of analysis, MPA comprises the ideational, the interpersonal and the textual levels which appear in each component. These levels of analysis correspond to Halliday's $(1978,1985,2004)$ three metafunctions or strands of meaning which are interconnected and operate simultaneously in the semantic system or "discourse-semantics" (Eggins 1994:81ff) of any language. In the present case, the focus is on the textual metafunction that concerns the clause when it has its meaning as "message" (Halliday 2004:64). It is the enabling and relevance function of language that brings texts or communicative events into being linguistically and through which what is said or written is seen as relevant. This function is linked to the mode of discourse in the register and to both the thematic structure and patterns of cohesion in the lexicogrammar. In spoken language, the thematic structure is supplemented by the information structure that is realised through intonation.

From a translational point of view, the textual metafunction will enable translators to draw profiles of linguistic features in the ST and the TT according to the norms operating in the source and target culture. Since cohesion is the manipulation of the elements in the Mood systems and coherence the manipulation of the propositional structures in the Transitivity systems (cf. Bell 1991:165), translators will be able to recreate a cohesive and coherent text according to the norms of the target language and culture. The text thus recreated will be functionally equivalent (Waard and Nida 1986) and not necessarily identical to its counterpart in the source culture. Such a TT is expected to satisfy the needs of the target audience.

In this respect, subtitlers will construct cohesive and coherent subtitles by taking into account all the semiotic resources - linguistic and non-linguistic - that occur in the film. Since film is a multimodal text par excellence and linguistic resources can be manipulated to meet the needs of the target audience, subtitlers have to select relevant elements that will be transposed into the subtitles and that will assist in the construction of meaning in the receiving or target 
system. During this process of selection and transfer of meaning, they will "choose to ignore those meanings that are represented in other semiotic modes" (Chuang 2006:375) as well as those elements that do not jeopardise the cohesion and coherence of subtitles.

In the grammar of visual design, the textual metafunction corresponds to the semiotic system of composition. This semiotic system of composition is, according to Kress and Van Leeuwen (1996:181), "the way in which the representational and interactive elements are made to relate to each other, the way they are integrated into a meaningful whole." It involves three interrelated systems which are: (i) information value, (ii) salience, and (iii) framing (cf. Kress and Van Leeuwen 1996:183). These systems apply to single pictures and to composite visuals or multimodal texts such as films, advertisements or any other text whose meaning is realised through a combination of semiotic modes.

Basically, the information value depends on the layout or the placement of elements in the visual representation and in their relation to one another. It can be centred or polarised (cf. Kress and Van Leeuwen 1996:206). Salience refers to those elements that attract the viewer's attention to different degrees. It depends on, for example, the placement of some elements in the foreground or background, their relative size, their contrasts in tonal value or colour, their differences in sharpness and their highlighting through either bolding, italicising or underlining (cf. Kress and Van Leeuwen 1996:186, 212). Framing refers to the presence or absence of specific devices which create dividing lines or boundaries within which the text and image are organised. It is common both to temporally integrated texts such as dance, music or connected speech and to spatially integrated compositions such as magazine pages, paintings or street maps (cf. Kress and Van Leeuwen 1996:214).

Of these three systems, framing plays the most important role in visual composition in that it marks off the elements or groups of elements from one another. For example, it separates the verbal from the visual in some multimodal texts such as press advertisements or television commercials. This framing of elements is variable in the sense that the elements may be strongly or weakly framed. The elements which are strongly framed are presented as separate units of information. The presence of framing creates a sense of individuality and differentiation. Its absence creates a group identity or a sense of belonging. In making films, for instance, framing leads filmmakers to choose between showing two or more actors together in one shot and using individual shots that separate one actor from the others by frame lines.

According to Kress and Van Leeuwen (1996:216ff), there are four possible ways in which framing can be realised. The first way is that the most salient objects will attract the viewer's attention and thus realise framing in pictures. The second way is to use frame lines which determine what the viewer is allowed to see or not to see. The third way is to mark off the elements from one another through discontinuities of colour and/or shape. The last way is to leave empty space between elements. In all these cases, vectors play a key role in that they lead the viewer's gaze from the most salient element to another, thereby establishing a connection between elements within the frame. They act as pointers and create visual coherence which is necessary for the reading of images.

In the context of interlingual subtitling, visual cohesion is created by taking into account the semiotic resources that enter into the composition of the "framed image" (Monaco 1981:149). In this respect, the semiotic resources of layout, framing and salience play a major role in that 
they not only integrate the representational and interactional elements in the frame but also affect both the viewer's reading paths and the visual coherence of these elements within the frame. Since film is a moving image text, attention is given to the camera movements in order to identify the salient elements and thus establish the connection between them.

In the grammar of sound design, however, there is no clear-cut division of the semiotic resources of sound into the three metafunctional configurations. This means that the semiotic resources of sound including perspective, time, rhythm, interacting sounds, melody, voice quality, timbre and modality are not structured along the metafunctional lines as the semiotic resources of language and visual imagery because of the nature of their semiotic mode (cf. Van Leeuwen 1999:190). These semiotic resources of sound embrace whole units of discourse and are suprasegmental to words, phrases, clauses, and sentences. They play a dual role in sound design since they stand for both presentation and representation. Thus, as Van Leeuwen (1999:190-191) suggests, there are times when they are used "both ideationally and interpersonally" and times when they are used "both ideationally and textually."

For this researcher, the semiotic resources of sound realise acoustic cohesion when there is harmony between presentation and representation, that is, when there is a match between a sound and the object it represents. One of these semiotic resources that plays a major role in creating acoustic cohesion is rhythm. The latter is "a regular pulse" (Van Leeuwen 1999:42) and "the code of temporal composition" (Kress and Van Leeuwen 1996:183). It contributes to the fusion of meanings which are expressed in and through the different semiotic modes that enter into the composition of multimodal discourse. It operates and provides cohesion in timebased multimodal texts and communicative events such as conversations, music, dance and film. Its fundamental principle is alternation which occurs between two opposite poles or states at regular intervals. Rhythm is thus determined in terms of the regularisation and patterns of time which characterise speech, music and sound effects.

Basically, rhythmic regularisation is achieved through tempo, the number of sounds or movements per measure, the number of measures per phrase, and the number of phrases per move. Rhythmic patterning is based on three major types of time. These are (i) measured and unmeasured time, (ii) metronomic and non-metronomic time, and (iii) monorhythmic and polyrhythmic time. Further details on rhythmic regularisation and rhythmic patterning can be found in Van Leeuwen (1999:39-60, 2005:189-196).

Another semiotic resource of sound that plays a crucial role in spoken discourse and contributes to creating acoustic cohesion is melody commonly referred to as intonation. The latter is the melody of a clause or a sentence. It characterises the speaker's attitudes in verbal interactions and is often used to signal grammatical distinctions between statements, questions, commands and exclamations. These grammatical distinctions are signalled through tone units that contain one nucleus and other stressed syllables that normally precede the nucleus. From a systemic functional perspective, intonation signals the Given-New system in the information structure of spoken texts. From a pragmatic and speaker-hearer perspective, it assists greatly in establishing coherence in conversational discourse and works as an illocutionary force-indicating device or IFID in Levinson's (1983:238) terminology.

In the context of interlingual subtitling, acoustic cohesion is created by taking into account the semiotic resources of sound and the objects they represent in the film. Since people identify sounds in terms of their acoustic structure and film is a polysemiotic text, the major semiotic 
resources that play an important role in establishing acoustic cohesion in the framed image are melody, rhythm and voice quality. For example, a rising-falling intonation in film dialogue is associated with a statement, a WH-question or a command, and a rising intonation with a yes/no question or an incomplete utterance. In the same vein, the sound of a steam train is associated with a train, and the sound of a car horn with a car. Thus, acoustic cohesion in the film frame is achieved by synchronising speech, music and sound effects with images and subtitles.

\subsection{Implications of an integrated approach for further research}

The adoption of an integrated approach to cohesion and coherence in interlingual subtitling has several implications for further research at the textual, visual and acoustic levels. At the textual level, adopting an integrated approach means researching the systems of cohesion relations including the relations of junction, reference, substitution, ellipsis, and semantic contiguity. It also means doing research on the FSP of a clause and on "pragmatic coherence" (Van Dijk and Kintsch 1983:149) or "conversational structure cohesion" (Eggins 1994:93, 109-111). Research on the FSP will focus on the thematic progression while research on pragmatic coherence will concentrate on the adjacency sequence of speech acts in the film dialogue and the subtitles.

At the visual level, adopting an integrated approach means researching the semiotic resources that contribute to visual cohesion. Research will focus on the construction and progression of meaning in the film either through pictures alone or through the interaction between pictures and language or between gesture and speech or text. Visual semiotic analysis will examine the effect of camera shots, angles and movements on cohesion. It will analyse the systems of information value, of salience and of framing to see how they contribute to cohesion in the film. The use of colour as a semiotic mode in guiding the viewer to particular readings of the filmic text will also be examined at this stage.

At the acoustic level, adopting an integrated approach means doing research on the semiotic resources that impact on acoustic cohesion. Research will concentrate on the construction and progression of meaning in the film through sound and sound effects. Sound semiotic analysis will consider the role of melody, rhythm, voice quality and other semiotic resources (cf. Van Leeuwen 1999) in creating acoustic cohesion in the filmic text. Particular attention will thus be given to the effect of these semiotic resources on the relation between speech and subtitles, on the one hand, and between music or sound effects and subtitles, on the other.

As should be clear from the above discussion, an integrated approach to cohesion and coherence includes a wide range of linguistic and non-linguistic aspects that are relevant to interlingual subtitling. Whereas the linguistic aspects have been widely discussed in other approaches, the non-linguistic aspects have been largely ignored or neglected. It is in this context that this paper has proposed an integrated approach to cohesion and coherence to facilitate the analysis of acoustic, verbal and visual aspects of cohesion and coherence in interlingual subtitling. It remains to say that this integrated approach is worth trying in AVT and that research is much needed in this area to improve the translation and subtitling of films at the cohesive level.

In Mubenga (in preparation), this theoretical discussion will be applied to the English subtitling of the French feature film Au revoir les enfants by Malle (1989). It will focus on the 
conjunctive cohesive markers that are used in this film to discover the translation shifts and to establish a taxonomy of these markers from a systemic functional perspective.

\section{References}

Austin, J.L. 1962. How to Do Things with Words. Oxford: Clarendon Press.

Baker, M. 1992. In Other Words: A Coursebook on Translation. London and New York: Routledge.

Bell, R.T. 1991. Translation and Translating: Theory and Practice. London and New York: Longman.

Blum-Kulka, S. 1986. Shifts of cohesion and coherence in translation. In J. House and S. Blum-Kulka (eds). Interlingual and Intercultural Communication: Discourse and Cognition in Translation and Second Language Acquisition Studies. Tubingen: Gunter Narr Verlag.

Brown, G. and G. Yule. 1983. Discourse Analysis. Cambridge: Cambridge University Press.

Charolles, M. 1983. Coherence as a principle in the interpretation of discourse. Text 3(1): 7197.

Chuang, Y.T. 2006. Studying subtitle translation from a multi-modal approach. Babel 52(4): 372-383.

Daneš, F. 1974. Functional sentence perspective and the organisation of the text. In F. Danes (ed.) Papers on Functional Sentence Perspective. Prague: Academia.

De Beaugrande, R.A. and W.U. Dressler. 1981. Introduction to Text Linguistics. London: Longman.

De Linde, Z. and N. Kay. 1999. The Semiotics of Subtitling. Manchester: St. Jerome.

De Saussure, F. 1959. Course in General Linguistics. Translated by Wade Baskin. New York: McGraw-Hill.

De Saussure, F. 1972 [1916]. Cours de Linguistique Générale. Paris: Payot.

Díaz Cintas, J. 2004. Subtitling: the long journey to academic acknowledgement. The Journal of Specialised Translation 1: 50-68.

Eggins, S. 1994. An Introduction to Systemic Functional Linguistics. London: Pinter.

Folkart, B. 1988. Cohesion and the teaching of translation. Meta 33(2): 142-155.

Grice, H.P. 1975. Logic and conversation. In P. Cole and J.L. Morgan (eds). Syntax and Semantics 3: Speech Acts. New York: Academic Press.

Gumul, E. 2008. Conjunctive cohesive markers: Translational shifts in English-Polish SI and CI. In B. Lewandowska-Tomaszczyk and M. Thelen (eds). Translation and Meaning: Part 8. Maastricht (The Netherlands): Zuyd University, Maastricht School of International Communication, Department of Translation and Interpreting.

Halliday, M.A.K. 1978. Language as Social Semiotic: The Social Interpretation of Language and Meaning. London: Edward Arnold.

Halliday, M.A.K. 2004 [1985]. An Introduction to Functional Grammar. $3^{\text {rd }}$ ed. Revised by Christian M.I.M. Matthiessen. London: Arnold.

Halliday, M.A.K. and R. Hasan. 1976. Cohesion in English. London: Longman.

Halliday, M.A.K. and R. Hasan. 1985. Language, Context, and Text: Aspects of Language in a Social-Semiotic Perspective. Geelong, Victoria: Deakin University.

Hatim, B. and I. Mason. 1990. Discourse and the Translator. London: Longman.

Hatim, B. and I. Mason. 1997. The Translator as Communicator. London and New York: Routledge.

Kachroo, B. 1984. Textual cohesion and translation. Meta 29(2): 128-134.

Kostopoulou, G. 2007. The role of coherence in text approaching and comprehension: Applications in translation didactics. Meta 52(1): 146-155. 
Kress, G. and T. van Leeuwen. 2006 [1996]. Reading Images: The Grammar of Visual Design. $2^{\text {nd }}$ ed. London and New York: Routledge.

Leech, G.N. 1983. Principles of Pragmatics. London: Longman.

Lehmann, D. 1985. La grammaire de texte: une linguistique impliquée? Langue Française 68: 100-114.

Levinson, S.C. 1983. Pragmatics. Cambridge: Cambridge University Press.

Malle, L. 1989. Au revoir les enfants. New York: Orion Home Video.

McNamara, D. 2001. Reading both high-coherence and low-coherence texts: Effects of text sequence and prior knowledge. Canadian Journal of Experimental Psychology 55(1): 51-62.

Monaco, J. 1981. How to Read a Film: The Art Technology, Language, History and Theory of Film and Media. Revised Edition. New York/Oxford: Oxford University Press.

Mubenga, K.S. 2008. Film Discourse and Pragmatics in Screen Translation: A Contrastive Analysis of Speech Acts in French and English. PhD Thesis. Johannesburg: University of the Witwatersrand.

Mubenga, K.S. 2009. Towards a multimodal pragmatic analysis of film discourse in audiovisual translation. Meta 54(3): 466-484.

Mubenga, K.S. In preparation. A systemic functional analysis of conjunction in the subtitling of Au Revoir les Enfants.

Newmark, P. 1987. The use of systemic linguistics in translation analysis and criticism. In R. Steele and T. Threadgold (eds). Language Topics: Essays in Honour of Michael Halliday. Volume 1. Amsterdam/Philadelphia: John Benjamins. Reprinted in P. Newmark. 1991. About Translation. Clevedon: Multilingual Matters.

Newmark, P. 1988. A Textbook of Translation. Hemel Hempstead: Prentice-Hall.

Searle, J.R. 1969. Speech Acts: An Essay in the Philosophy of Language. Cambridge: Cambridge University Press.

Searle, J.R. 1975. Indirect speech acts. In P. Cole and J.L. Morgan (eds). Syntax and Semantics 3: Speech Acts. New York: Academic Press.

Toury, G. 1995. Descriptive Translation Studies - And Beyond. Amsterdam/Philadelphia: John Benjamins.

Van Dijk, T.A. and W. Kintsch. 1983. Strategies of Discourse Comprehension. New York: Academic Press.

Van Leeuwen, T. 1999. Speech, Music, Sound. Houndmills and London: MacMillan.

Van Leeuwen, T. 2005. Introducing Social Semiotics. London and New York: Routledge.

Waard, J. de and E.A. Nida. 1986. From One Language to Another: Functional Equivalence in Bible Translating. Nashville: T. Nelson.

Woods, W.A. 1970. Transition network grammars for natural language analysis. Communications of the Association for Computing Machinery 13: 591-606. 